\title{
NOVOS ARRANJOS FAMILIARES: PATERNIDADE, PARENTALIDADE E RELAÇÕES DE GÊNERO SOB O OLHAR DE MULHERES CHEFES DE FAMÍLIA
}

\author{
Juliana Perucchi* \\ Aline Maiochi Beirão**
}

\section{RESUMO}

Cresce no Brasil o número de lares chefiados por mulheres, novos arranjos familiares pertinentes à análise da psicologia. O presente artigo é o relato de uma pesquisa que buscou investigar as concepções que mulheres chefes de família têm sobre a paternidade. A coleta de dados se fez por entrevistas semi-estruturadas com mulheres, mães, que mantinham sozinhas o sustento familiar. As entrevistas foram analisadas por meio da análise de conteúdo. Os resultados apontam que as concepçôes que essas mulheres têm a respeito da paternidade são atravessadas por suas vivências pessoais e pelas experiências que marcaram sua trajetória familiar, contemplando noções acerca da parentalidade e das relações de gênero. São concepções que remetem à valorização de uma perspectiva do pai participativo e presente, não apenas como provedor, mas, fundamentalmente, como educador. Concepções construídas a partir de um fazer cotidiano reconhecido por elas como próprios de pais e de mães, em funções que elas afirmam desempenhar concomitantemente.

Palavras-chave: paternidade, parentalidade, mulheres chefes de família

* Psicóloga; Mestre em Psicologia Social; Doutoranda do Programa de Pós-graduação em Psicologia da Universidade Federal de Santa Catarina (UFSC); Pesquisadora do Núcleo MARGENS/UFSC; Professora da Associação Catarinense de Ensino (ACE) em Joinville, Santa Catarina.

** Graduada em Psicologia pela Universidade para o Desenvolvimento do Alto Vale do Itajaí (UNIDAVI); formada em Orientação Profissional pelo Instituto do Ser; Psicóloga do Centro de Referência da Assistência Social de Rio do Sul, Santa Catarina. 


\begin{abstract}
NEW FAMILY ARRANGEMENTS: CONCEPTIONS ABOUT PATERNITY, PARENTHOOD AND GENDER RELATIONS IN FEMALE HEADS OF HOUSEHOLDS

The number of households headed by women is growing in Brazil. This article is the result of a research that investigated the conceptions that female heads of households have about paternity. The data was gathered through semi-structured interviews with women, mothers, who were solely in charge of household income. The interviews were later submitted to content analysis. The results show that the conceptions that these women have about paternity are crossed by their personal experiences and the experiences that have marked their family trajectory. These notions contemplate the themes of parenthood and gender relations. The participative and present father, not only as a supplier, but, basically, as an educator, is praised in their conceptions. Those conceptions are constructed from the daily tasks they carry out, which they consider as being the functions of both fathers and mothers, but which they execute concomitantly.

Keywords: paternity, parenthood, female heads of households
\end{abstract}

\title{
INTRODUÇÃO
}

O número de lares chefiados por mulheres está crescendo vertiginosamente no Brasil, revelando uma posição social cada vez mais ocupada por mulheres no contexto atual das famílias brasileiras: a de provedoras do sustento da família. Esta realidade cada dia mais comum no país caracteriza arranjos familiares que contrariam os preceitos do patriarcado, contestam modelos tradicionais e revelam paisagens até então desconhecidas ou pouco evidenciadas. Neste contexto de transformações, as pesquisas a respeito destes novos arranjos familiares tornam-se relevantes para produções teóricas da psicologia.

O presente artigo é fruto de uma pesquisa que focalizou a paternidade como categoria de análise - sob a visão de mulheres chefes de família residentes em uma região do interior do Estado de Santa Catarina. As temáticas acerca da parentalidade e das desigualdades de gênero no mundo do trabalho aparecem como "pano de fundo", contemplando discussões acerca dos desdobramentos e das práticas sociais oriundas desses novos arranjos familiares. Foram analisados nos relatos das mulheres chefes de família os sentidos atribuídos à paternidade. Depoimentos embasados em sua história de vida, constituída pelas relações estabelecidas em um contexto de emancipação feminina e de crise do modelo familiar patriarcal. Foram entrevistadas dez mulheres, responsáveis pelo sustento de seus filhos e que se reconhecem como provedoras de suas famílias. O acesso a estas mulheres se deu por meio do trabalho em Psicologia Clínica, uma vez que as autoras perceberam a recorrência de casos atendidos cujas clientes encontravam- 
se neste perfil: mulheres mães que mantinham sozinhas o sustento do lar e de seus filhos, ou seja, a sustentação financeira da família. A análise dos dados foi pautada na análise de conteúdo (Bardin, 1985). Este trabalho privilegia a análise das categorias à luz das teorias feministas e da Psicologia Sócio-Histórica e busca estabelecer um diálogo fértil e pertinente entre os estudos de gênero e a Psicologia Clínica.

O crescimento de famílias chefiadas por mulheres, assim como de outras configurações familiares diferentes do modelo tradicional, tem sido vertiginoso nas sociedades ocidentais, cuja organização sociocultural foi tradicionalmente pautada em um modelo patriarcal (Castells, 1999). Segundo o Relatório Nacional Brasileiro sobre a implementação da plataforma de ação da IV Conferência Mundial da Mulher - Pequim, 1995 -, a porcentagem de mulheres na População Economicamente Ativa (PEA) cresceu de 31,3\% em 1981, para 35,5\% em 1990, chegando em 1998 a 40,7\%. Dados das Pesquisas Nacionais por Amostragens em Domicílios (PNAD) em 1998 evidenciaram que, entre os anos de 1993 e 1998, a proporção de mulheres entre as pessoas economicamente ativas com escolaridade igual ou superior ao ensino médio passou de $23,2 \%$ para $29,7 \%$, enquanto que para os homens essa proporção passou de $16,3 \%$ para $20,7 \%$. No ano de 2000 , o percentual de mulheres chefes de família no Brasil era de uma em cada quatro famílias, $18,1 \%$ da População Economicamente Ativa.

Nesse contexto socioeconômico da realidade brasileira, a família e as relações de parentalidade são temas que têm sido discutidos pela psicologia e entendidos como construçôes sociais estabelecidas a partir de vínculos genéticos e/ou de convívio. Construçôes que se processam em campos sociais marcados por relações de afeto e de poder. A temática da paternidade, por sua vez, tem encontrado espaço na psicologia, principalmente pelos estudos de gênero ancorados na vasta produção dos estudos feministas. Siqueira (1997) já propunha uma interlocução desses dois campos teóricos tendo como foco a temática da identidade masculina.

Houve um avanço nos últimos anos em relação ao aumento de pesquisas sobre a paternidade e a saúde reprodutiva dos homens, que colocam em xeque velhos estereótipos sobre o pai frio, autoritário, insensível, que não manifesta afeto por seus filhos (Bilac, 1996; Giffin \& Cavalcanti, 1999; Lyra da Fonseca, 1998). Mesmo que apontem para certas tendências gerais de modos de se exercer a masculinidade, esses estudos destacam a diversidade de modelos de paternidade e de comportamentos dos pais para com seus filhos e a família na contemporaneidade (Fonseca, 2004).

As pesquisas referentes às posiçôes sociais assumidas por homens e mulheres no panorama das famílias brasileiras tornam-se relevantes para produções teóricas 
no campo da psicologia. Nesse sentido, o presente artigo aborda a paternidade como categoria de análise e contempla discussões transversais: as novas exigências feitas aos homens que ocupam a posição de pai; a demanda por relações de gênero igualitárias no contexto familiar e no mundo do trabalho; a divisão da responsabilidade na educação dos filhos proveniente, sobretudo, das transformações no código civil brasileiro. Enfim, propõe-se neste texto um debate sobre paternidade, parentalidade e relações de gênero sob a ótica de mulheres chefes de família, protagonistas das transformaçōes na sociedade brasileira.

\section{Metodologia}

As informantes da pesquisa foram dez mulheres mães, responsáveis pelo sustento de seus filhos, reconhecidas como mulheres chefes de família e residentes no interior do Estado de Santa Catarina. Estas informantes se caracterizaram também pela ausência de coabitação com cônjuge e/ou companheiro. Elas foram contatadas por meio da rede social do universo da atuação clínica das pesquisadoras, seguindo a proposta metodológica na qual "a identificação desses elementos pode ser feita com a ajuda de informantes que, por suas características e/ou funções, tenham amplo conhecimento do contexto estudado" (Alves-Mazzotti \& Gewandsznajder, 1999: 162). O fato de que a maioria das informantes possuía múltiplas jornadas de trabalho, divididas entre o cumprimento da carga-horária no(s) emprego(s) e os afazeres que envolvem a administração da casa e cuidados aos filhos, criou uma dificuldade para agendar algumas entrevistas. Superado este problema por meio da adequação dos horários das pesquisadoras ao tempo disponível das informantes, foi realizada a coleta de dados por meio de entrevista semiestruturada. De acordo com Alves-Mazzotti e Gewasndsznajder (1999), nestas entrevistas o pesquisador formula perguntas específicas, mas também abre espaço para que o entrevistado possa responder com seus próprios termos. Neste sentido, as falas das informantes, como processo de linguagem, apresentaram-se como campo fértil para identificar suas significaçôes: "entendemos a linguagem ao mesmo tempo como mediação da subjetividade e como instrumento produzido social e historicamente, materializando assim as significaçôes construídas no processo social e histórico" (Aguiar, 2002: 130).

As informantes que participaram da pesquisa possuíam mais de 30 anos, escolaridade mínima de segundo grau incompleto e pelo menos dois filhos. A ausência de coabitação com cônjuge caracterizou-se por se tratar de informantes viúvas, separadas ou divorciadas, sendo que uma das informantes se considera casada (não juridicamente) com o pai de seus filhos, mas não coabita com ele. A 
maioria das mulheres é chefe de família há mais de dez anos; apenas uma das entrevistadas é responsável pelo sustento da família há menos de um ano.

A análise seguiu a proposta metodológica da análise de conteúdo (Bardin, 1985). Por meio deste procedimento metodológico, as falas das informantes foram organizadas por meio da identificação dos núcleos de significação, ou seja, identificação dos temas centrais do relato das participantes. Os objetivos da pesquisa nortearam a organização dos temas centrais afins em cada núcleo. A função de colocar estes dados em núcleos é organizar a análise, possibilitando uma compreensão profunda do sentido global das narrativas (Aguiar, 2002).

\section{Resultados}

As concepções que mulheres chefes de família possuem sobre a paternidade são embasadas em suas histórias de vida, em vivências constituídas nas relações estabelecidas em um contexto social, histórico e cultural. Tais concepções estão permeadas pelos conhecimentos socialmente produzidos e acumulados ao longo da história, compartilhados coletivamente e apropriados pelos sujeitos por meio das relaçôes sociais que subsidiam as mediações sígnicas para a ação humana.

As entrevistas evidenciam a responsabilidade exclusiva por parte destas mulheres no sustento de seus dependentes. Entretanto, as redes sociais familiares de duas das informantes entrevistadas auxiliam de modo a complementar esporadicamente o sustento, no que tange às necessidades das crianças menores de idade.

$\mathrm{Na}$ maioria dos casos, estas mulheres continuam sustentando os filhos mesmo na maioridade ou prestando suporte financeiro. Além da responsabilidade de todas as entrevistadas pelo sustento dos filhos, uma delas tem como dependente a mãe e outra tem os netos menores de idade. Em todos os relatos, verificou-se que os dependentes moram junto com a mãe, chefe da família.

A respeito da forma como estas mulheres mantêm seus dependentes, constatou-se que nove delas trabalham e uma é aposentada há seis anos. Esse perfil de mulheres profissionais reflete a entrada das mulheres no mercado de trabalho, configurando um panorama atual que destaca a conquista do espaço público e de certa autonomia financeira. As estratégias de manutenção do sustento familiar caracterizam-se pela presença de trabalhos formais e informais, de atividades com e sem registro na carteira de trabalho, sendo todas elas na área de prestação de serviços. A preocupação constante no controle de gastos dentro das possibilidades impostas pela renda de cada uma das informantes também aparece como um dado relevante.

Sobre as dificuldades encontradas no mercado de trabalho por ser chefe de família, verifica-se ainda a forte presença da perspectiva patriarcal embasando pré-julgamentos. 
As múltiplas jornadas de trabalho, as estratégias para conciliar as responsabilidades domésticas com vida profissional, os diferentes níveis de exigências de produção do mercado, além da responsabilidade pelos cuidados aos filhos, foram dificuldades apontadas.

A colagem do papel de mãe às mulheres apresentou-se como dificuldade para inserção e manutenção dessas mulheres no mercado de trabalho. A maternidade remete a um papel social entendido e construído como "naturalizado". Em um contexto de mercado impregnado pela lógica patriarcal, as mulheres chefes de família parecem estar em desvantagem. A elas são atribuídas diferentes concepçôes acerca das possíveis limitaçôes ou perdas no rendimento profissional quando tentam conciliar dedicação ao emprego com atividades do espaço familiar. Outra grande dificuldade apontada foi a concorrência no mercado de trabalho e a necessidade de constante atualização profissional.

Sobre a responsabilidade no cuidado aos filhos, questionou-se às informantes sempre em relação à época em que os filhos eram menores de idade. Estas mulheres assumem a responsabilidade pelo cuidado aos filhos tanto na educação quanto na manutenção financeira, nas atividades do tempo livre, de lazer e de auxilio nas tarefas escolares.

Redes de apoio com a participação de empregadas domésticas, creches e escolas, em alguns casos, auxiliam no cuidado aos filhos no momento de ausência da mãe no cumprimento de sua carga horária no emprego. As informantes atribuíram a responsabilidade dos cuidados aos filhos para si, sem maiores críticas ou contestações. Mesmo quando havia coabitação com o marido, segundo alguns relatos, ao pai cabia uma participação esporádica e modesta, de acordo com as possibilidades dele. Nesse sentido, destacam-se elementos já analisados em estudos anteriores, nos quais se constata que pais e mães assumem funções específicas na educação dos filhos e que o cuidado da casa e dos filhos permanece sob responsabilidade da mãe (Wagner, 2003).

As redes sociais familiares se mostram um auxílio predominante, tanto para o cuidado aos filhos como para os afazeres domésticos nos momentos de ausência destas mulheres no período em que estão em seus empregos. Estas redes sociais familiares são majoritariamente femininas: filha mais velha, avó, irmã, mãe, etc e se caracterizam por ser uma forma de socialização e compartilhamento de responsabilidades. Vale destacar que estudos desenvolvidos no Brasil afirmam que "as mulheres que sustentam a casa desempenham mais tarefas domésticas do que as mulheres dependentes economicamente de seus maridos, proporcionalmente ao tempo disponível que possuem" (Wagner, Predebon, Mosmann \& Verza, 2005: 182). Essas autoras apontam também que pesquisas brasileiras e norte-americanas 
têm evidenciado a manutenção de padrōes relativamente tradicionais na divisão das tarefas domésticas. "Estudos brasileiros com famílias de nível socioeconômico médio nos quais a mulher é a principal responsável pelo sustento financeiro mostram que ela ainda assume quase que totalmente a responsabilidade pelas tarefas domésticas" (Wagner e cols., 2005: 182).

Dentre as dificuldades vinculadas às responsabilidades das mulheres chefes de família, a escassez de recursos financeiros foi ressaltada como uma dificuldade permanente. Tal escassez atribuída a fatores econômicos e sociais, mesmo sendo uma dificuldade predominantemente apontada nos relatos das informantes, não ocasionou a privação de necessidades básicas como, por exemplo, a alimentação dos filhos.

Foram destacados nos relatos das informantes concepções acerca da ausência do cônjuge e das dificuldades em assumir as responsabilidades que, antes, eram conferidas a ele. A experiência de tomar para si funções concebidas como próprias da figura paterna, por exemplo, é definida como algo que exige muita responsabilidade. Nesta mesma perspectiva, a resolução de problemas no espaço público e o encaminhamento de situações culturalmente caracterizadas como tarefas masculinas foram assumidos pelas mulheres na ausência do marido ou companheiro.

A conquista do mundo do trabalho sem a diminuição das atividades no espaço doméstico e as conseqüentes dificuldades provenientes dessas múltiplas jornadas, assim como as exigências frente ao estilo de vida caracterizado pela responsabilidade de sustentar a família, perpassam os relatos das informantes. Neste sentido, a fala dessas mulheres elucida conflitos referentes ao confronto entre o estilo de vida por elas assumido e a lógica patriarcal. Ainda que as mulheres chefes de família componham um arranjo familiar contraditório à lógica patriarcal, encontram-se resquícios dela em seus relatos. As práticas sociais destas mulheres contrárias a essa lógica - e a presença de resquícios patriarcais em seus relatos evidenciam o movimento dialético dos contrários e a dimensão simbólica da constituição da subjetividade (Vygotsky, 1992).

Sobre as concepções das informantes acerca da paternidade, pôde-se verificar que a maioria delas se reconhece desempenhando funçōes paternas e maternas. A distinção dos papéis de pai e mãe foi feita por meio de construções sociais de gênero no que tange às atribuições de masculino/feminino, construídas a partir das diferenças sociais atribuídas às diferenças sexuais. As construçôes de gênero, baseadas no modelo patriarcal, ficaram evidentes na fala das informantes, relacionando a maternidade à sensibilidade e à submissão e a paternidade à força e à atividade. O pai continua a ocupar, nessas concepções, um lugar de respeito e de autoridade sobre a família. 
A importância da participação do pai na educação foi apontada em todas as falas como fundamental na construção da personalidade das crianças. A ausência do pai, agregada ao estereótipo do modelo patriarcal de paternidade, ou seja, a vinculação do pai à figura que exerce autoridade sobre os filhos, aparece na fala das informantes como um elemento dificultador na educação destes. Esta figura é caracterizada pela autoridade plena e exclusiva do pai sobre os filhos, cabendo-lhe a função de estabelecer limites, impor regras de conduta, delimitar simbolicamente o que é e o que não é permitido. Esta concepção fica clara quando uma das informantes coloca a necessidade de ela ter "mais pulso firme" na educação dos filhos, como conseqüência da ausência de um pai na família, e a necessidade de se colocar em uma posição culturalmente concebida como masculina.

A relação pai/autoridade apareceu de modo recorrente nos relatos das informantes. Contudo, nenhuma delas caracterizou a paternidade a partir de uma perspectiva patriarcal, ou seja, como sendo uma relação pai/provedor com seus filhos/ dependentes. A tarefa de prover foi colocada não como uma exclusividade do pai e sim como algo a ser compartilhado pelo casal. As informantes atribuíram à paternidade uma função de participação efetiva em tudo o que engloba educação dos filhos, principalmente no que tange ao campo da afetividade.

Os relatos das informantes sobre a paternidade, de modo geral, demonstram uma tentativa de superação do papel de pai como provedor da família, o que sugere que estas mulheres demandam uma maior participação do pai de seus filhos (seja pai biológico ou pai social) na dinâmica sócio-afetiva da família. Não apareceu nas falas das informantes nenhuma intenção de compartilhar os afazeres domésticos com um companheiro. Tampouco destacaram qualquer necessidade de ter, no contexto do lar, a presença de um pai para compartilhar responsabilidades. O compartilhamento de responsabilidades aparece no relato dessas mulheres como restrito à educação dos filhos em um contexto mais amplo. $\mathrm{O}$ espaço doméstico apresenta-se no imaginário dessas mulheres ainda como um território predominantemente feminino, mesmo com a concepção da exigência de responsabilidades mútuas entre homens e mulheres no cuidado aos filhos.

\section{Discussão}

Elas são marianas, lúcias, elviras e tantas outras que assumem a chefia de suas famílias, a responsabilidade pela educação dos filhos e pelo sustento da casa. Mulheres com duplas e até triplas jornadas de trabalho que constroem a si mesmas e às suas concepções sobre o mundo e sobre suas vidas no desempenho diário das funções sociais exigidas pela condição que assumiram. É neste contexto que 
tais mulheres se posicionam, crítica ou espontaneamente, diante do tema paternidade. Não como um conceito abstrato, etéreo ou sublime, mas como um fenômeno constitutivo de sua práxis. Paternidade e maternidade estão inexoravelmente vinculadas, seja como categorias de análise, seja como práticas sociais e, como tal, impreterivelmente arraigadas à dinâmica social dos novos arranjos familiares.

De acordo com Lane (1995), os significados das palavras são construídos em um contexto sócio-histórico e são processados e transformados por indivíduos concretos, em um movimento de subjetivação da objetividade e seguinte objetivação da subjetivação, como um "retorno" através de ações concretas.

As concepções que essas mulheres têm a respeito da paternidade são atravessadas por suas vivências pessoais e pelas experiências que marcaram sua trajetória familiar. Aparecem diretamente relacionadas ao domínio de atividades referentes ao espaço público e reconhecidas culturalmente como atividades próprias dos homens. Concepções românticas sobre a figura do pai participativo e presente, não apenas como provedor, mas, fundamentalmente, como educador. Concepções construídas a partir de um fazer cotidiano reconhecido por elas como próprias, tanto às funções de pais quanto às funções de mães, em posições que elas parecem desempenhar concomitantemente: "o indivíduo, apesar de ser único, contém a totalidade social e a expressa nas suas ações, pensamentos e sentimentos. Assim, o processo aprendido (e não manifestaçôes internas; respostas) a partir de um sujeito pode revelar algo constitutivo de outros sujeitos que vivem condições semelhantes" (Aguiar, 2002: 140).

Partindo do pressuposto da crise no modelo familiar patriarcal como uma realidade que se evidencia na contemporaneidade, verificou-se que a figura paterna parece ocupar outros lugares no universo de significações e sentidos dessas mulheres chefes de família.

Segundo Mollon (1999), os signos são uma espécie de controle do outro atuando sobre o sujeito e que passará para o controle do sujeito. Dessa forma acontece o processo interpessoal, na relação com o outro, que se transformará em processo intrapessoal e que retornará ao outro por meio da linguagem. É nesse processo de criação e utilização dos signos, mediado pela linguagem, que o sujeito se constitui. O processo de construção intrapsicológica, via função interpsicológica, passa pelo crivo do contexto sócio-histórico.

Assim, as concepções de paternidade que atravessam o relato das informantes são também atravessadas pelas vivências e pelas formas como essas mulheres se constituem. Em outras palavras, através do processo inter e intrapsicológico, na relação dialética entre objetividade e subjetividade, estas mulheres constroem sentidos particulares daquilo que, anteriormente, compartilham coletivamente nas 
redes de sociabilidade. Tais concepções são construídas por meio de um complexo processo pelo qual experiências individuais são engendradas por produções sociais historicamente construídas e coletivamente compartilhadas. Por esse processo, o sujeito imprime singularidade às suas ações no mundo, na mesma medida em que é constituído por múltiplos vínculos das suas redes de relações, ou seja, pelas ações de outros sujeitos.

Construindo o referencial sócio-histórico, Vygotsky (1992) afirma que o significado da palavra é permanentemente estável. O que se altera, de acordo com o contexto, é o sentido atribuído particularmente pelo sujeito. São os sentidos atribuídos à paternidade que se modificam e se transformam nas falas dessas mulheres - sentidos construídos em um contexto de emancipação feminina e de crise do modelo familiar patriarcal nas sociedades contemporâneas.

A paternidade se constitui, na fala dessas mulheres que chefiam famílias, como uma prática exercida no âmbito das relaçôes familiares, mas também se constitui como posição simbólica a ser ocupada por certos sujeitos, em determinadas circunstâncias. O sujeito se constitui pelas significaçôes culturais e a significação não existe em si. Ela está imersa nas relações estabelecidas pelo sujeito e condicionadas às circunstâncias sociais.

O modelo patriarcal de família, caracterizado pelo arranjo composto por pai, mãe e filhos que convivem sob a égide da autoridade do primeiro sobre os demais, está em crise. Nesse modelo, o pai desempenha o papel social de provedor do sustento da família e ocupa o lugar socialmente legitimado de autoridade sobre a mulher e os filhos. Tal crise vem de longa data, devido a uma realidade construída historicamente pelas lutas de emancipação feminina e de conscientização das mulheres em um contexto de transformações no mercado de trabalho, na ciência tecnológica e na economia globalizada (Castells, 1999). A decadência do modelo familiar patriarcal propicia novas concepções de papéis sociais e pauta (re)configuraçōes da família moderna. Adaptando-se às transformaçōes, as novas famílias criam espaços para que diferentes formas de relações sejam estabelecidas.

O contexto atual caracteriza-se por todas essas transformações na família, que inevitavelmente se estendem para o mercado de trabalho. Entretanto, o mundo do trabalho, mesmo apresentando avanços, continua preso à lógica patriarcal. As mulheres chefes de família - cujas práticas sociais se apresentam como contradição ao modelo tradicional - sofrem as conseqüências da desvalorização do seu trabalho. É inegável o peso que as construções sociais de gênero têm sobre a sociedade, especialmente no que tange ao "ser mulher" como detentora da responsabilidade pelos trabalhos domésticos e pela educação dos filhos (Castells, 1999; Lago, 1986). 
Como o trabalho feminino tem sido tradicionalmente considerado como complemento ao salário do marido e como as mulheres ainda são responsáveis pelos trabalhos domésticos e, principalmente, pela criação dos filhos, a flexibilidade em relação ao emprego ajusta-se também a estratégias de sobrevivência, para que possam dar conta desses dois mundos que as colocam, com freqüência, no limite de um esgotamento nervoso (Castells, 1999: 208).

Vale destacar que, conforme afirmam Teixeira e Perucchi (2001), as mulheres em geral recebem salários inferiores e menos benefícios do que os homens. Essa lógica, contrária à equidade de gênero, mantém-se como base para decisões de planejamento de carreira e para definições de cargos e de salários no mercado de trabalho formal.

Compreender a paternidade nesse contexto é questionar a produção de conceitos baseados na estabilidade da família e contestar a concepção de papéis fixos e naturalizados. Analisar as concepções sobre a paternidade em uma configuração familiar não tradicional - em que os papéis da mulher e do homem são menos rígidos - é uma forma de entender as funções que os sujeitos desempenham nas relações sociais que estabelecem.

De acordo com Bilac (1996), a conquista do espaço público, o controle da fertilidade e a expansão da educação formal trouxeram transformações para a condição feminina. Entretanto, estas não foram transformações que propiciaram uma maior igualdade nas relaçôes de gênero no interior da família. Se, por um lado, a mulher teve conquistas na esfera da produção, por outro, acabou aumentando sua carga de responsabilidades. Às responsabilidades do âmbito doméstico - tradicionalmente atribuídas às mulheres - somaram-se as de âmbito público. A autora questiona se estas transformações realmente correspondem a um aumento da participação masculina no âmbito privado ou se, ao contrário, aumentaram a desigualdade de gênero, minimizando ainda mais a participação masculina e maximizando a participação feminina no que se refere à família.

A pesquisa constatou que as informantes designam-se como responsáveis exclusivas pelo sustento de seus filhos, havendo, em muitos casos, suporte financeiro de redes sociais familiares. Além dos filhos, algumas delas possuem outros familiares como seus dependentes. Na maioria dos casos, elas permanecem responsáveis também pelo sustento dos filhos maiores de idade. As mulheres chefes de família se reconhecem desempenhando concomitantemente funções de pai e de mãe em relação aos filhos, sendo que estas são funções diferenciadas por elas a partir das concepções de masculinidade e feminilidade legitimadas socialmente. 
De acordo com Comel (1998), historicamente as relaçôes entre pais e filhos sempre possuíram de certa forma um caráter privado e natural. A naturalização e a privatização dessas relações dificultavam a crítica e a produção de estudos científicos sobre o caráter sócio-histórico-cultural dessas relações.

Em todos os relatos, a paternidade esteve vinculada à participação efetiva dos pais na educação dos filhos. Atribui-se à educação a responsabilidade na construção da história dos filhos, em todos os aspectos, sobretudo no âmbito da afetividade e da autoridade.

A relação pai/provedor foi superada de acordo com todos os relatos, sendo que a tarefa de prover apresentou-se como uma possibilidade combinada à educação dos filhos. A tarefa de educar sobressai à de prover.

A superação do modelo pai/provedor esteve presente no relato de todas as informantes, enquanto que o modelo pai/autoridade foi confirmado. Portanto, a evidência dessa investigação aponta para a existência de um movimento dialético acerca das concepções de paternidade no universo investigado. Constatou-se não apenas a mudança, mas também a conservação de elementos presentes anteriormente. Portanto, a negação de certos modelos não significa que foram extintos do imaginário social, mas sim que outros se configuram e também se transformam no âmbito das relações materiais e históricas que os sujeitos estabelecem no meio social.

\section{REFERÊNCIAS BIBLIOGRÁFICAS}

Aguiar, W. M. J. (2002). A pesquisa em psicologia sócio-histórica: contribuições para o debate metodológico. Em Bock, A. M. B.; Gonçalves, M. G. M. \& Furtado, O. Psicologia Sócio-histórica: uma perspectiva crítica em psicologia (pp. 129-140). São Paulo: Cortez. Alves-Mazzotti, A. J. A. \& Gewandsznajder, F. (1999). O método nas Ciências Naturais e Sociais: pesquisa quantitativa e qualitativa. São Paulo: Pioneira.

Bardin, L. (1985). Análise de conteúdo. Lisboa: Ediçōes 70.

Bilac, E. D. (1996). Mãe certa, pai incerto: da constituiçãa social à normatização jurídica da paternidade e da filiação. Grupo de Trabalho Família e Sociedade da XX Reunião Anual da ANPOCS, Caxambu, MG.

Castells, M. (1999). O poder da identidade. São Paulo: Paz e Terra.

Comel, N. E. D. (1998). Paternidade responsável: o papel do pai na sociedade brasileira e na educação familiar. Curitiba: Juruá.

Fonseca, C. (2004). A certeza que pariu a dúvida: paternidade e DNA. Revista de Estudos Feministas, 12, 2, 13-34. 
Giffin, K. \& Cavalcanti, C. (1999). Homem e reprodução. Revista Estudos Feministas, 7, $1-2,53-71$.

Lago, M. C. S. (1986). Trabalho feminino, trabalho improdutivo? Revista de Ciências Humanas, 8, 129-133.

Lane, S. T. M. \& Codo, W. (1995). Psicologia Social: o homem em movimento. São Paulo: Brasiliense.

Lyra da Fonseca, J. (1998). Paternidade adolescente: da investigação à intervenção. Em Arilha, M.; Ridenti, S. G. U. \& Medrado, B. (Orgs.). Homens e masculinidades: outras palavras (pp. 185-214). São Paulo: ECOS/Editora 34.

Mollon, S. I. (1999). Subjetividade e constituição do sujeito em Vygotsky. São Paulo: EDUC. Siqueira, M. J. T. A. (1997). A constituição da identidade masculina: alguns pontos para discussão. Psicologia, 8, 1, 113-130.

Teixeira, J. P. \& Perucchi, J. (2001). Uma mulher afirmativa. Anita Pires: mulher no singular, política no plural, empresária do social. Florianópolis: Cidade Futura.

Wagner, A. (2003). A família e a tarefa de educar: algumas reflexões a respeito das famílias tradicionais frente a demandas modernas. Em Féres-Carneiro T. (Org.). Família e casal: arranjos e demandas contemporâneas (pp. 27-33). Rio de Janeiro: Ed. Loyola.

Wagner, A.; Predebon, J.; Mosmann, C. \& Verza, F. (2005). Compartilhar tarefas? Papéis e funções de pai e mãe na família contemporânea. Psicologia: Teoria e Pesquisa, 21, 2, $181-186$.

Vygotsky, L. S. (1992). Pensamiento y palabra. Obras Escogidas II. Madrid: Visor.

Recebido em 29 de julho de 2007 Aceito para publicação em 26 de novembro de 2007 